\title{
The Anesthesiologist's Role in the Prevention of Surgical Site Infections
}

\author{
William J. Mauermann, M.D., ${ }^{*}$ Edward C. Nemergut, M.D.†
}

CME www.asahq.org/journal-cme to take the test and apply for Category 1 credit. Complete instructions may be found in the CME section at the back of this issue.

SURGICAL site infections (SSIs) continue to be a substantial source of morbidity and mortality in the surgical patient population. They are the second most common cause of nosocomial infection after urinary tract infections and account for approximately $17 \%$ of all hospital-acquired infections. ${ }^{1}$ These infections lead to longer hospital and intensive care unit stays, lead to substantially increased mortality, and contribute significantly to healthcare costs. ${ }^{2}$ In a 1999 series of cardiac surgery patients, each deep sternal wound infection added an average of $\$ 26,400$ in hospital charges and increased the average duration of stay by 16 days. ${ }^{3}$

The incidence of SSI varies for each operative procedure, each surgeon, and each hospital. In addition, each patient presents with his or her own unique risk profile for the development of a SSI. Although sterile surgical technique is extremely important to the prevention of SSIs, there is increasing evidence that anesthesiologists play a prominent yet under appreciated role in the prevention of SSIs. While infections typically present several days postoperatively, the first few hours after bacterial contamination are the critical window for the establishment of infection. ${ }^{4,5}$ Therefore, decreasing SSIs hinges on the optimization of perioperative conditions, many of which are controlled by anesthesiologists.

In this review, we will discuss the literature surrounding six perioperative factors over which anesthesiologists have at least partial control and how these factors

* Resident Physician in Anesthesiology, † Assistant Professor of Anesthesiology and Neurosurgery.

Received from the Department of Anesthesiology, University of Virginia Health System, Charlottesville, Virginia. Submitted for publication October 17, 2005. Accepted for publication March 23, 2006. Support was provided solely from institutional and/or departmental sources.

The illustrations in this section were prepared by Dimitri Karetnikov, 7 Tennyson Drive, Plainsboro, New Jersey 08536.

Address correspondence to Dr. Nemergut: University of Virginia Health System, P. O. Box 800710, Charlottesville, Virginia 22908-0710. en3x@virginia.edu. Individual article reprints may be accessed at no charge through the Journal Web site, www.anesthesiology.org. may influence the risk of postoperative surgical site infection. Although we acknowledge that many anesthesiologists care for patients in the intensive care unit, we limit our discussion here to the immediate perioperative period.

\section{Hypothermia}

Mild perioperative hypothermia (core body temperature $34^{\circ}-36^{\circ} \mathrm{C}$ ) is commonly observed in surgical patients. The complications of mild perioperative hypothermia have been studied extensively and include increased duration of hospitalization, ${ }^{5}$ increased intraoperative blood loss and transfusion requirements, increased adverse cardiac events, and an increase in patient thermal discomfort in the recovery room. ${ }^{6}$ The effects of mild hypothermia on SSI have also been studied.

A series of 200 patients undergoing colorectal surgery were randomized to a hypothermic group $\left(34.4^{\circ} \pm\right.$ $\left.0.4^{\circ} \mathrm{C}\right)$ or a normothermic group $\left(37^{\circ} \pm 0.3^{\circ} \mathrm{C}\right)$ and followed for 2 weeks postoperatively. ${ }^{5}$ The authors had planned to enroll 400 patients; however, the trial was stopped early because of a statistically significant difference in infection between the two groups. The incidence of SSI was $5.8 \%$ in the normothermic group and $18.8 \%$ in the hypothermic group. The patients who developed SSIs required hospital stays nearly 1 week longer than those who did not develop a SSI, indicating that these were clinically significant complications. The normothermic patients were also found to have significantly more collagen near the wound, had their staples removed a day sooner, and tolerated food earlier. ${ }^{5}$ In addition, the authors determined that intraoperative vasoconstriction was present in $74 \%$ of the hypothermic patients but only $6 \%$ of the normothermic patients. This difference remained statistically significant throughout the 6-h recovery period. ${ }^{5}$

This randomized, double-blind trial suggests hypothermia is a major risk factor for postoperative SSI and that maintenance of perioperative normothermia may reduce the incidence of SSIs. One criticism of this study has focused on the increased allogeneic blood requirement in the hypothermic group $(0.8 \pm 1.2 v s .0 .4 \pm 1.0$ units $P=0.01$ ). Indeed, erythrocyte transfusions have been 
implicated as a risk factor for SSI and will be discussed in detail below. In their discussion, these authors state that "on multivariate regression analysis a requirement for transfusion did not independently contribute to the incidence of wound infection." 5 Further, although the hypothermic patients received more allogenic blood per patient, the number of patients requiring transfusion was not significantly different $(P=0.054)$.

In 2001, Flores-Maldonado et $a l^{7}$ reported on a series of 290 consecutive cholecystectomy patients with a 30day follow-up. This series excluded patients that received blood transfusions preoperatively, intraoperatively, or postoperatively. The average temperature in their hypothermic group was $35.4^{\circ} \pm 0.4^{\circ} \mathrm{C}$ versus $36.2^{\circ}$ $\pm 0.2^{\circ} \mathrm{C}$ in the normothermic group based on tympanic membrane immediately postoperatively. The incidence of SSI was $11.5 \%$ in the hypothermic group and $2 \%$ in the normothermic group. ${ }^{7}$ This study implicates mild hypothermia as a risk factor for SSI but excludes the possible contribution of perioperative blood transfusion.

Although a few studies have not shown an increased risk of infection in hypothermic patients,${ }^{8}$ most studies, including those reviewed here, implicate mild intraoperative hypothermia as a risk factor for postoperative SSI. Indeed, Kurz et al. ${ }^{5}$ performed the only double-blind randomized trial evaluating hypothermia and found a strong correlation between hypothermia and infection. Although the authors acknowledge that this study may not necessarily reflect current practice (in the study, the antibiotics were administered during anesthesia induction and may not have preceded skin incision as is currently recommended, and antibiotics were continued for 4 postoperative days) and that the study only observed patients undergoing colorectal surgery, it is likely that the findings are applicable to other surgical patient populations today. With all that is now known regarding the complications of hypothermia, ${ }^{6}$ it should be every clinician's goal to maintain normothermia unless contraindicated.

The major relation between hypothermia and increased SSI is thought to be a decrease in subcutaneous tissue perfusion mediated by vasoconstriction. ${ }^{9}$ Hopf $e t$ al. ${ }^{10}$ demonstrated that subcutaneous oxygen tension at a surrogate wound inversely correlated with the risk of SSI. In patients with a subcutaneous oxygen tension greater than $90 \mathrm{mmHg}$, there were no infections, whereas patients with a subcutaneous oxygen tension of $40-50 \mathrm{mmHg}$ had an infection rate of $43 \% .{ }^{10}$ This illustrates the critical importance of providing adequate oxygen stores to maintain oxidative killing by neutrophils. Not only does hypothermia decrease perfusion and thus oxygen supply to the wound, it also reduces the production of superoxide radicals for any given oxygen tension. Indeed, bacterial killing by neutrophils is reduced in the face of hypothermia. ${ }^{6}$ In addition, animal models have demonstrated that hypothermia induces an antiinflam- matory T-cell cytokine profile with increased levels in interleukin 10 and decreased levels of interleukin 2. This profile is similar to that of other "proinfectious" states such as severe burn and hemorrhage. It should also be noted that mild hypothermia increases nitrogen losses and decreases collagen production, which may serve to slow would healing and contribute to the risk of infection. ${ }^{5,11}$ These points are summarized in figure 1 .

Heat loss during the first hour of anesthesia is typically a result of the redistribution of core to peripheral temperature gradients caused by an anesthetic-induced decrease in vasoconstriction. Actively prewarming patients for $2 \mathrm{~h}$ before the induction of either general or regional anesthesia can attenuate this effect. ${ }^{6}$ The two most important causes of continued heat loss in the operating room are radiation and convection. The most effective means of preventing these causes of ongoing losses are forced air warming and administration of warmed fluids. ${ }^{6}$ Many detailed reviews exist on the causes, treatment, and prevention of perioperative hypothermia. ${ }^{6,9,12}$

\section{Hyperoxia}

In most clinical situations, oxygen delivery is vastly more dependent on the amount of oxygen bound to hemoglobin than the amount of oxygen dissolved in the blood. However, the subcutaneous tissue consumes little oxygen compared with the rest of the body, approximately $0.7 \mathrm{ml} / 100 \mathrm{ml}$ of blood. ${ }^{13}$ This amount of oxygen can be supplied by the plasma alone in a normal perfusion state. ${ }^{13}$ In fact, the mean extracellular partial pressure of oxygen in the subcutaneous tissue is around 60 $\mathrm{mmHg}$, a level above the range in which oxygen readily dissociates from hemoglobin. In addition, trauma-induced injury of the microvasculature at the site of the wound increases the diffusion distance required for oxygen, further decreasing the impact of hemoglobin transported oxygen on wound oxygen tension. Adequate wound oxygen tension is important not only for oxygen radical production by neutrophils (fig. 1) but also in the development of collagen and epithelium, instrumental factors in wound healing. ${ }^{13}$

These facts have led some researchers to hypothesize that providing supplemental oxygen during the perioperative period would lead to higher oxygen tensions in the wound and a decrease in the incidence of SSIs. To date, two randomized, double-blind trials involving 800 patients for elective colorectal surgery have evaluated the effects $80 \%$ inspired oxygen versus $30 \%$ inspired oxygen intraoperatively and for $2 \mathrm{~h}$ (500 patients) or $6 \mathrm{~h}$ (300 patients) postoperatively. Both of these studies found statistically significant reductions in the rates of SSIs in the 0.8 fraction of inspired oxygen $\left(\mathrm{FIO}_{2}\right)$ group versus the $0.3 \mathrm{FIO}_{2}$ group. ${ }^{14,15}$ Pooling the data from 


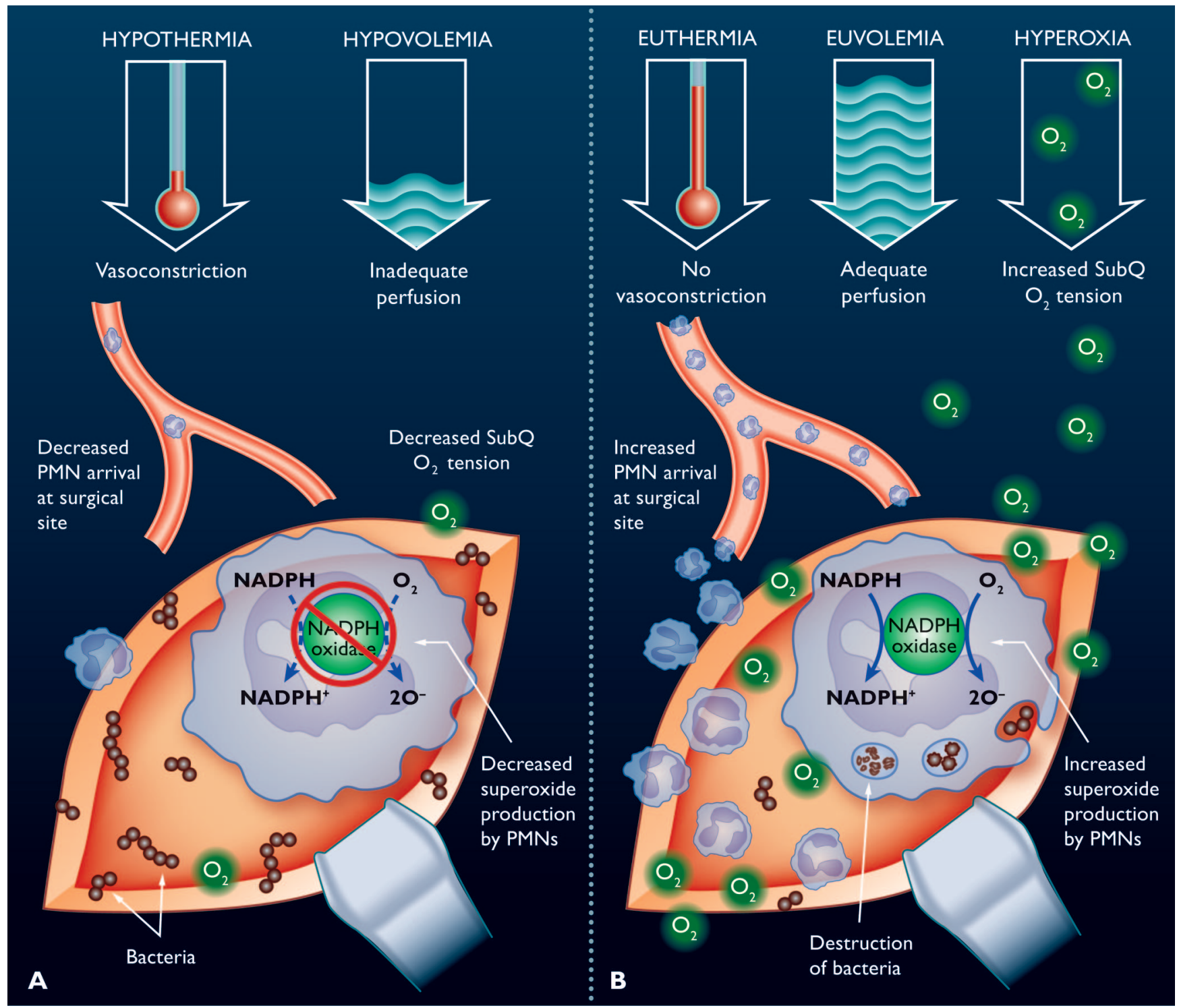

Fig. 1. Conditions leading to decreased $(A)$ and increased $(B)$ oxygen tension. Decreases in subcutaneous oxygen increase the incidence of surgical site infection. The maintenance of normothermia and adequate perfusion are important interventions that increase subcutaneous oxygen and help to prevent surgical site infection. The use of increased fractions of inspired oxygen or hyperoxia may also provide significant benefit. $\mathrm{NADPH}=$ nicotinamide adenine dinucleotide phosphate; $\mathrm{O}_{2}=$ oxygen; $\mathrm{PMN}=$ polymorphonuclear cell; SubQ = subcutaneous.

these two studies yields an absolute risk reduction in SSI of $7 \%$ and a relative risk reduction of $45 \%(P=0.02) .{ }^{16}$ Although halving the rate of SSI after colorectal surgery with a simple maneuver such as increasing the inspired oxygen percentage to $80 \%$ would have broad implications, the findings of these authors have not been supported by other studies. Pryor et al. ${ }^{17}$ reported a study of 160 patients undergoing major abdominal surgery including hemicolectomy, sigmoidectomy, low anterior resection, gastrectomy, pancreaticoduodenectomy, exploratory laparotomy, and large gynecologic staging or debulking procedures. They randomized patients to either $35 \%$ inspired oxygen or $80 \%$ inspired oxygen. The assigned oxygen level was also maintained for $2 \mathrm{~h}$ postoperatively. This study was terminated at interim analy- sis secondary to a statistically significant increase in the rate of SSI in the $80 \%$ oxygen group. ${ }^{17}$

It is difficult to reconcile the results of these three randomized, double-blind studies with opposing results. An editorial provides a potential explanation of these conflicting results. ${ }^{16}$ The study by Pryor et al. is limited by its smaller size. In addition, perioperative conditions were not standardized between groups, as they were in the two positive studies. The patient groups in the study of Pryor et al. were also not as closely matched, the blinding was less rigorous, and the determination of SSI was retrospective as opposed to the prospective evaluation that was performed in the two positive studies. ${ }^{16}$ It would seem from two well-done, randomized trials that high-inspired oxygen levels in the perioperative period 
confers some benefit in reducing the incidence of SSIs. Although there is one study with nearly an opposite outcome, this study is likely outweighed by the larger patient populations in two positive trials. While providing $80 \%$ inspired oxygen in the operating room is simple and likely without significant risk, the continuation of high $\mathrm{FiO}_{2}$ for 2- $6 \mathrm{~h}$ postoperatively is not without potential procedural complications and delays in moving patients out of the recovery room. Therefore, the question still remains as to whether high inspired oxygen levels intraoperatively, without continuation into the recovery room, would confer the same benefit.

\section{Perioperative Fluid Management}

Although the subcutaneous tissue requires little total oxygen, wound healing and the prevention of infection are critically dependent on adequate perfusion to deliver oxygen. ${ }^{10}$ Also important to oxygen delivery is the maintenance of an adequate perfusion state by the preservation of euvolemia. ${ }^{18}$ Appropriate fluid management in surgical patients has been studied and debated for decades, and the discussion surrounding SSIs and fluid management is no less unsettled.

Perioperative physicians typically administer intravenous fluids to replace fasting deficits, third space losses, and blood loss with a goal of maintaining adequate cardiac output, blood pressure, and urine output. However, mild to moderate total body hypovolemia is well tolerated by relatively healthy adults as interstitial fluid moves into the intravascular space to help preserve cardiac output. This may result in adequate renal function with preserved urine output and hemodynamic stability while leaving the subcutaneous tissue relatively hypovolemic. By measuring subcutaneous tissue oxygen tensions in postoperative patients, it has been shown that increasing intravascular volume can improve oxygen tensions in previously underperfused patients (fig. 1). ${ }^{18}$

The hypothesis that aggressive fluid administration would better maintain subcutaneous perfusion and wound oxygen tension was tested in a randomized, double-blind trial. Fifty-six patients undergoing elective colon surgery were randomized to receive traditional fluid management $\left(8-10 \mathrm{ml} \cdot \mathrm{kg}^{-1} \cdot \mathrm{h}^{-1}\right.$ intraoperatively and $1 \mathrm{~h}$ postoperatively) or aggressive fluid management $\left(10 \mathrm{ml} / \mathrm{kg}\right.$ bolus followed by $16-18 \mathrm{ml} \cdot \mathrm{kg}^{-1} \cdot \mathrm{h}^{-1}$ intraoperatively and $1 \mathrm{~h}$ postoperatively). Additional fluid was given to both groups in a 3:1 ratio to replace blood loss and for urine output less than $1 \mathrm{ml} \cdot \mathrm{kg}^{-1} \cdot \mathrm{h}^{-1}$ or blood pressure less than $70 \%$ of baseline. Although patients in the aggressively hydrated group had statistically significant higher intraoperative and postoperative tissue oxygen tension, no outcome data regarding the incidence of SSIs was presented. ${ }^{19}$ This trial was subsequently expanded in a randomized, prospective manner to measure clinical outcomes. The authors could not show a statistically significant difference in the incidence of SSI or wound-healing scores with aggressive versus traditional fluid management. ${ }^{20}$

The use of colloids has also been evaluated with regard to improving tissue oxygen tension. Lang et al. ${ }^{21}$ have shown that using hydroxyethyl starch intraoperatively and postoperatively decreases the amount of crystalloid required to maintain stable hemodynamics and urine output while increasing the tissue oxygen tension. In this study, the colloid group had an increase in tissue oxygen tension of $54 \%$, whereas a group of similar patients who received crystalloid had a $29 \%$ decrease in tissue oxygen tension. ${ }^{21}$

Although there is evidence that aggressive fluid management and the use of hydroxyethyl starch improve tissue oxygenation, the only trial that reported on the incidence of SSI with aggressive hydration did not show any statistically significant improvement in the incidence of SSI. In addition, concern over decreased pulmonary function and bowel edema leading to an increase in the time to return of GI function have tempered enthusiasm for aggressive fluid management in general surgical patients. A recent randomized trial has shown that restricting intravenous fluids to patients undergoing major abdominal procedures resulted in fewer complications, improved times to return of gastrointestinal function, decreased wound-healing complications, and shortened the duration of hospital stay by 1 day. ${ }^{22}$ At this time, it seems that aggressive fluid resuscitation does not decrease the incidence of SSI, and maintenance of euvolemia is recommended based on clinical parameters.

\section{Hyperglycemia}

It has been well established that patients with diabetes are at increased risk for infections, including SSIs. Even in nondiabetics, hyperglycemia is associated with an increased risk of morbidity and mortality. ${ }^{23}$ In one recent trial, the use of insulin infusions to maintain serum glucose at less than $110 \mathrm{mg} / \mathrm{dl}$ in critically ill patients decreased the mortality rate from $8.0 \%$ to $4.6 \%$ regardless of diabetes status. In fact, $87 \%$ of the study population had no history of diabetes. The bulk of the reduction in mortality occurred by reducing the incidence of multi- organ system failure with septic focus. ${ }^{24}$ Although it is unknown whether this data from the intensive care unit can be extrapolated to the perioperative setting, it has spawned an interest in studying the effects of glucose control on the risk of SSI. The majority of study in this area has taken place in cardiac surgery patients. ${ }^{3,24-27}$ However, there is emerging evidence that stringent glucose control may reduce the rates of SSI in a variety of surgical populations. ${ }^{28}$

Several recent studies have now shown a correlation 
Fig. 2. Hyperglycemia induces a host of negative effects on the normal immune response in a surgical wound. IgG $=\mathrm{im}$ munoglobulin G; PMN = polymorphonuclear cell; $\mathrm{WBC}=$ white blood cell.
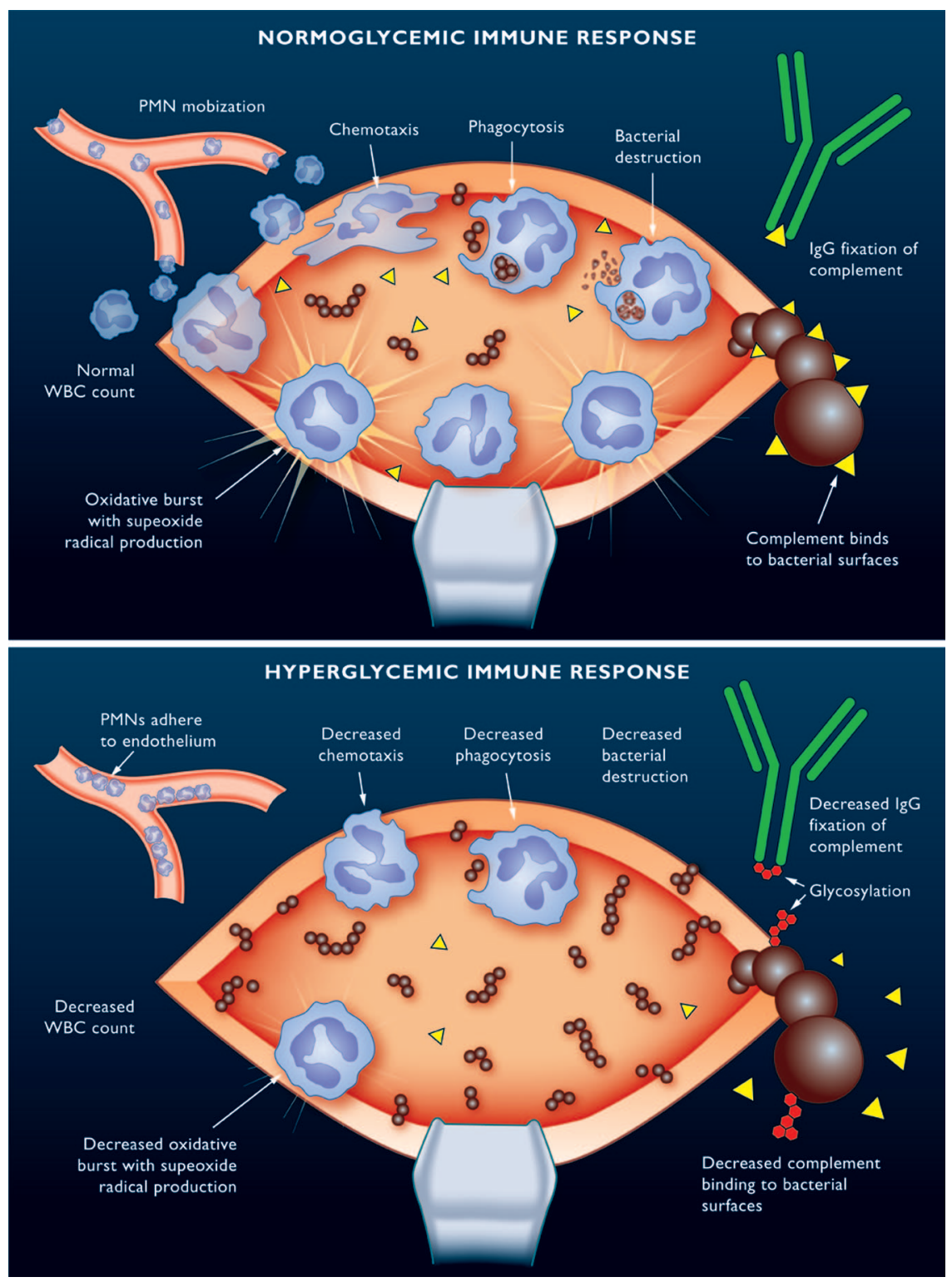

between hyperglycemia and the risk of SSI (fig. 2). ${ }^{29-32}$ The most devastating of these infectious complications in cardiac surgery patients are deep sternal wound infections, potentially leading to mediastinitis, which increases operative mortality twofold to threefold. ${ }^{3}$

Two series from the same institution studied the effects of implementing a continuous insulin infusion to maintain blood glucose levels between 150 and 200 $\mathrm{mg} / \mathrm{dl}$ in diabetic patients undergoing cardiac surgery. Patients in the continuous insulin infusion groups were matched with historic controls who had received sliding scale insulin every $4 \mathrm{~h}$ with a goal of maintaining glucose levels less than $200 \mathrm{mg} / \mathrm{dl}$. These authors noted a $66 \%$ reduction in the incidence of deep sternal wound infections in diabetic patients using continuous insulin infusions. ${ }^{3,26}$ It is important to note that insulin infusions were continued into the postoperative period during this study. This indicates the relative importance of optimizing perioperative conditions, not simply isolated intraoperative conditions.

Numerous studies have attempted to elucidate the effects of hyperglycemia on immune function. A glucose challenge in healthy subjects has been shown to induce a transient reduction in leukocyte counts and all lymphocyte subsets. Hyperglycemia also results in the effective deactivation of immunoglobulins by nonenzymatic glycosylation. In addition, the glycosylation of the $\mathrm{C} 3 \mathrm{com}$ ponent of complement blocks binding to bacterial surfaces. As discussed above, neutrophils play an important role in preventing even mildly contaminated wounds from developing infections. Numerous functional deficits have been shown in the neutrophils of diabetic patients. These include impaired chemotaxis, decreased phagocytic ability, and lower bactericidal capacity. ${ }^{33}$ In 
in vitro studies, it has been shown that these functions can be at least partially restored by a normoglycemic environment. ${ }^{34}$

One study examined in vivo neutrophil function in cardiac surgery patients whose glucose was aggressively controlled with an insulin infusion and compared them with patients whose glucose was controlled with insulin boluses at a standard level for that institution. These authors found that neutrophil phagocytic function was better preserved at $1 \mathrm{~h}$ after separation from cardiopulmonary bypass in the aggressively controlled patients versus the standard controls. ${ }^{27}$

Although randomized trials studying the effects of glucose control in the perioperative setting are lacking, a body of evidence is emerging to support tighter glucose control at the time of surgery. The fact that hyperglycemia is associated with increased morbidity and mortality, regardless of diabetic status, underscores the importance of maintaining a low threshold for measuring glucose levels in any patient thought to be at risk of developing increased perioperative glucose levels. Although currently available data do not allow the authors to recommend a specific threshold for the treatment of hyperglycemia, there is ample evidence to suggest that only treating blood glucose greater than $200 \mathrm{mg} / \mathrm{dl}$ (as has traditionally been suggested) is inappropriate. Indeed, aggressive treatment of hyperglycemia with insulin and frequent measures of serum glucose levels is quickly becoming an established standard. ${ }^{35}$

\section{Blood Transfusion and the Risk of Infection}

Allogeneic blood transfusions are known to have important immunomodulatory effects. ${ }^{36,37}$ More than 100 studies have now been published regarding the transfusion of blood products and the risk of postoperative infection. Unfortunately, small cohorts and retrospective design limit modern interpretation. Further confounding the issue is the fact that early studies often used whole blood, which is rarely used now. In addition, currently produced packed erythrocyte units contain less than $10 \%$ plasma and less than 5\% leukocytes versus units produced in the 1970 s. Finally, the hemorrhage that often necessitates transfusion has itself been shown to increase infectious risk.

Regardless, many recent prospective studies have linked perioperative transfusion to infection in multiple surgical populations including cardiac surgery, ${ }^{38}$ orthopedic surgery, ${ }^{39}$ trauma, $^{40}$ and colorectal surgery. ${ }^{41} \mathrm{Al}-$ though these studies imply that the transfusion of blood products increases the risk of infection, some studies have not noted an increased risk, ${ }^{42}$ and others have argued that the effect of transfusion is minor. ${ }^{37}$ Nevertheless, the risk of infection with transfusion can be decreased using autologous blood donation ${ }^{37}$ versus al- logenic blood. In fact, in most studies, the infection rates with autologous blood approach those of patients who did not have transfusion. This point lends further evidence to the causal relation between allogeneic packed erythrocyte transfusions and the risk of infection. ${ }^{37}$

Most of the discussion in the literature surrounding the immunomodulatory effects of transfusion implicates donor leukocytes. ${ }^{36,43}$ To this end, leukoreduction has thought to potentially be helpful. Indeed, some countries have already implemented policies for universal leukocyte reductions and this issue is debated in the United States. ${ }^{43}$ Retrospective analysis in 23 centers throughout Canada showed that after adoption of a national leukoreduction program, cardiac surgery, hip fracture, and trauma patients had decreased mortality rates and a decreased incidence of antibiotic therapy, but serious nosocomial infections did not decrease. ${ }^{44}$ To date, the results of multiple randomized controlled trials have been reported. Meta-analysis of these trials using all randomized patients shows no significant difference in infection rate. ${ }^{43}$ However, in some of the trials, patients were included on an intention-to-treat basis, and thus their data were included regardless of whether they received a transfusion. When the pooled data were reanalyzed excluding patients who did not have transfusion, a significant reduction in the risk of wound infection when leukoreduced packed erythrocytes were used. As these authors note, their results should be viewed with caution because intention-to-treat analysis is considered to be the most conservative analytical approach. ${ }^{43}$ Another study also did not demonstrate an association between postoperative infections and the use of leukocyte-depleted blood in cardiac surgery patients; however, an increased incidence of postoperative infections was again observed with blood transfusions in general. $^{45}$

This issue has generated an impressive amount of literature, discussion, and argument. There is no doubt that transfusion has an immunomodulatory effect, but the true clinical impact and the most effective methods of prevention are still hotly debated. At this point, there are not adequate clinical data to support the use of wound infection in the risk-benefit analysis of transfusion.

\section{Antimicrobial Prophylaxis}

Perhaps the simplest and most effective role the anesthesiologist can play in the prevention of SSIs is ensuring the administration of appropriate antimicrobial prophylaxis. The goal of perioperative antibiotic administration is to obtain blood and tissue drug levels that exceed the minimum inhibitory concentration of the organisms likely to be encountered. ${ }^{46}$ The National Surgical Infection Prevention Project, a project created by the Centers 
for Medicare and Medicaid Services and the Centers for Disease Control, recently released an advisory statement. ${ }^{46}$ Much of the information will be summarized below; however, all perioperative physicians should familiarize themselves with this statement. Indeed, there are significant data indicating that initial physician compliance with advisory statements is poor. ${ }^{47}$ There are also data to suggest that compliance is improved when anesthesia teams take responsibility for administration of prophylactic antibiotics. ${ }^{48}$

\section{Timing}

The first clinical trial in 1969 showed that administering preoperative antibiotics to patients undergoing bowel surgery could decrease the incidence of wound infection and sepsis. This trial also showed that the most effective time period for administration was $1 \mathrm{~h}$ before incision. Patients who received the first antibiotic dose postoperatively received almost no benefit in terms of preventing infection. ${ }^{49}$

Multiple studies have since indicated that effective antibiotic administration is dependent on developing adequate blood and tissue drug levels (above minimum inhibitory concentration) before incision. ${ }^{49}$ Current recommendations state that infusion of the first dose of drug should begin within $60 \mathrm{~min}$ of incision. This period can be lengthened to $120 \mathrm{~min}$ for drugs such as vancomycin, where high infusion rates have been associated with complications. If a tourniquet is to be used, it is critical that administration of the antibiotic dose be completed before tourniquet inflation. ${ }^{46}$ It should be noted that these guidelines are based largely on the retrospective data only.

It should also be noted that due to a lack of benefit and the potential for the selection of resistant organisms, guidelines suggest that antimicrobial prophylaxis should end within $24 \mathrm{~h}^{46}$

\section{Choice of Antibiotic}

The ideal perioperative antibiotic prophylaxis focuses therapy at the most commonly encountered organisms. Prophylaxis should not be administered with the goal of covering all possible pathogens, because this may lead to the selection of drug resistant bacteria. For most surgeries not violating chronically colonized organs, the most common pathogens will be skin flora microbes, specifically the Streptococcus and Staphylococcus species. A first-generation cephalosporin (i.e., cefazolin) adequately covers these organisms in a cost-effective manner. Surgeries involving the bowel necessitate gram-negative and anaerobic coverage for which cefoxitin and cefotetan are appropriate. ${ }^{46}$

Although the routine use of vancomycin for surgical prophylaxis is not supported by any national recommendations, there is some discussion that vancomycin may be the prophylaxis of choice when a "cluster of MRSA [methicillin-resistant Staphylococcus aureus] mediastinitis or incisional SSI due to methicillin-resistant, coagulase-negative staphylococci has been detected."50 Some have suggested that vancomycin should be the prophylaxis of choice at institutions with a high prevalence of MRSA infection; however, there is no evidence that this practice decreases the incidence of MRSA infections. ${ }^{46}$

\section{$\beta$-Lactam-Allergic Patients}

A common problem physicians face is finding the most effective treatment for patients with $\beta$-lactam allergies. Ten percent of all patients studied in one series reported that they had a penicillin allergy, ${ }^{51}$ and other estimates range from $5 \%$ to $20 \%$. Multiple studies, though, have shown that the number of truly allergic patients is much lower. ${ }^{46,52}$ Regardless, these patients must be taken at their word when they present for surgery, given the significant morbidity associated with perioperative anaphylaxsis. $^{53}$ The question then becomes how best to approach a presumed $\beta$-lactam-allergic patient.

Early trials of cephalosporins revealed cross-reactivity in penicillin allergic patients. These patients had a rate of anaphylaxis of approximately $8 \% .^{54}$ Therefore, the standard of care became the avoidance of cephalosporins in these patients. However, the early cephalosporins contained a side chain similar to the penicillin side chain and were often contaminated with penicillin that was used in the synthetic process. This may have led to these high rates of cross-reactivity. Multiple studies have now shown the relative clinical safety of administering cephalosporins to penicillin allergic patients. ${ }^{55}$

As a result of the above evidence as well as other studies, algorithms are now available for managing these patients. Although skin testing for penicillin allergy has been shown not to be effective in predicting subsequent reactions to cephalosporins, ${ }^{46}$ skin testing against cephalosporins in any patient who has had a life-threatening reaction to penicillin before administration of a cephalosporin is one potential option. ${ }^{56}$ Indeed, a cost-analysis study showed that skin testing of patients with a history of penicillin allergy was more cost-effective than the routine use of vancomycin in these patients. ${ }^{57}$ Alternatively, patients with minor reactions to penicillin can be challenged with a cephalosporin. ${ }^{58}$ If the potential for allergic reaction to a cephalosporin is deemed high, vancomycin and clindamycin are reasonable alternatives for prophylaxis. ${ }^{46}$ Last, it should be noted that patients with a true penicillin allergy are more likely to experience an anaphylactic reaction to other drugs. ${ }^{59}$

\section{Conclusion}

Despite advances in surgical technique and the care of postoperative patients, SSIs remain an important cause of patient morbidity and mortality. There are at least six 
perioperative factors that may play a role in the prevention of this serious complication.

For some of these factors, there are strong data supporting their implementation. A multitude of studies exist indicating that hypothermia is harmful to many surgical patients on several levels, including an increased risk of SSIs. The timing and selection of antibiotics are important not only in preventing SSIs, but also in decreasing adverse events such as the selection of multidrug-resistant organisms. Although clinical evidence that supports abandoning historic glucose goals (approximately $200 \mathrm{mg} / \mathrm{dl}$ ) has yet to be shown in multiple studies, there is strong evidence from the critical care literature supplemented by emerging data from the perioperative period that normoglycemia may be an appropriate goal. Optimization of the perioperative environment by the anesthesiologist can have an important affect on the incidence of SSIs.

The authors thank Robert G. Sawyer, M.D. (Associate Professor, Department of Surgery, University of Virginia Health System, Charlottesville, Virginia), for his helpful comments regarding the manuscript.

\section{References}

1. National Nosocomial Infections Surveillance (NNIS) report, data summary from October 1986-April 1996, issued May 1996: A report from the National Nosocomial Infections Surveillance (NNIS) System. Am J Infect Control 1996; 24:380-8

2. Kirkland KB, Briggs JP, Trivette SL, Wilkinson WE, Sexton DJ: The impact of surgical-site infections in the 1990s: Attributable mortality, excess length of hospitalization, and extra costs. Infect Control Hosp Epidemiol 1999; 20:725-30

3. Furnary AP, Zerr KJ, Grunkemeier GL, Starr A: Continuous intravenous insulin infusion reduces the incidence of deep sternal wound infection in diabetic patients after cardiac surgical procedures. Ann Thorac Surg 1999; 67: 352-60

4. Miles AA, Miles EM, Burke J: The value and duration of defense reactions of the skin to primary lodgement of bacteria. Br J Exp Pathol 1957; 38:79-97

5. Kurz A, Sessler DI, Lenhardt R: Perioperative normothermia to reduce the incidence of surgical-wound infection and shorten hospitalization. Study of Wound Infection and Temperature Group. N Engl J Med 1996; 334:1209-15

6. Sessler DI: Complications and treatment of mild hypothermia. ANESTHESIOLOGY 2001; 95:531-43

7. Flores-Maldonado A, Medina-Escobedo CE, Rios-Rodriguez HM, FernandezDominguez R: Mild perioperative hypothermia and the risk of wound infection. Arch Med Res 2001; 32:227-31

8. Barone JE, Tucker JB, Cecere J, Yoon MY, Reinhard E, Blabey RG Jr, Lowenfels AB: Hypothermia does not result in more complications after colon surgery. Am Surg 1999; 65:356-9

9. Sessler DI, Akca O: Nonpharmacological prevention of surgical wound infections. Clin Infect Dis 2002; 35:1397-404

10. Hopf HW, Hunt TK, West JM, Blomquist P, Goodson WH III, Jensen JA, Jonsson K, Paty PB, Rabkin JM, Upton RA, von Smitten K, Whitney JD: Wound tissue oxygen tension predicts the risk of wound infection in surgical patients. Arch Surg 1997; 132:997-1004

11. Carli F, Emery PW, Freemantle CA: Effect of peroperative normothermia on postoperative protein metabolism in elderly patients undergoing hip arthroplasty. Br J Anaesth 1989; 63:276-82

12. Sessler DI: Mild perioperative hypothermia. N Engl J Med 1997; 336: $1730-7$

13. Hunt TK, Hopf HW: Wound healing and wound infection: What surgeons and anesthesiologists can do. Surg Clin North Am 1997; 77:587-606

14. Belda FJ, Aguilera L, Garcia de la Asuncion J, Alberti J, Vicente R, Ferrandiz L, Rodriguez R, Company R, Sessler DI, Aguilar G, Botello SG, Orti R, Spanish Reduccion de la Tasa de Infeccion Quirurgica Group: Supplemental perioperative oxygen and the risk of surgical wound infection: A randomized controlled trial. JAMA 2005; 294:2035-42

15. Greif R, Akca O, Horn EP, Kurz A, Sessler DI: Supplemental perioperative oxygen to reduce the incidence of surgical-wound infection. Outcomes Research Group. N Engl J Med 2000; 342:161-7

16. Dellinger EP: Increasing inspired oxygen to decrease surgical site infec- tion: Time to shift the quality improvement research paradigm. JAMA 2005; 294:2091-2

17. Pryor KO, Fahey TJ III, Lien CA, Goldstein PA: Surgical site infection and the routine use of perioperative hyperoxia in a general surgical population: A randomized controlled trial. JAMA 2004; 291:79-87

18. Jonsson K, Jensen JA, Goodson WH III, West JM, Hunt TK: Assessment of perfusion in postoperative patients using tissue oxygen measurements. Br J Surg 1987; 74:263-7

19. Arkilic CF, Taguchi A, Sharma N, Ratnaraj J, Sessler DI, Read TE, Fleshman JW, Kurz A: Supplemental perioperative fluid administration increases tissue oxygen pressure. Surgery $2003 ; 133: 49-55$

20. Kabon B, Akca O, Taguchi A, Nagele A, Jebadurai R, Arkilic C, Sharma N, Ahluwalia A, Galandiuk S, Fleshman J, Sessler DI, Kurz A: Supplemental intravenous crystalloid administration does not reduce the risk of surgical wound infection. Anesth Analg 2005; 101:1546-53

21. Lang K, Boldt J, Suttner S, Haisch G: Colloids versus crystalloids and tissue oxygen tension in patients undergoing major abdominal surgery. Anesth Analg 2001; 93:405-9

22. Nisanevich V, Felsenstein I, Almogy G, Weissman C, Einav S, Matot I: Effect of intraoperative fluid management on outcome after intrabdominal surgery Anesthesiology 2005; 103:25-32

23. Capes SE, Hunt D, Malmberg K, Gerstein HC: Stress hyperglycaemia and increased risk of death after myocardial infarction in patients with and without diabetes: A systematic overview. Lancet 2000; 355:773-8

24. van den Berghe G, Wouters P, Weekers F, Verwaest C, Bruyninckx F, Schetz M, Vlasselaers D, Ferdinande P, Lauwers P, Bouillon R: Intensive insulin therapy in the critically ill patients. N Engl J Med 2001; 345:1359-67

25. Ouattara A, Lecomte P, Le Manach Y, Landi M, Jacqueminet S, Platonov I, Bonnet N, Riou B, Coriat P: Poor intraoperative blood glucose control is associated with a worsened hospital outcome after cardiac surgery in diabetic patients. ANESTHESIOLOGY 2005; 103:687-694

26. Zerr KJ, Furnary AP, Grunkemeier GL, Bookin S, Kanhere V, Starr A: Glucose control lowers the risk of wound infection in diabetics after open heart operations. Ann Thorac Surg 1997; 63:356-61

27. Rassias AJ, Marrin CA, Arruda J, Whalen PK, Beach M, Yeager MP: Insulin infusion improves neutrophil function in diabetic cardiac surgery patients. Anesth Analg 1999; 88:1011-6

28. Brown M, Kroll H, Jordan J: Perioperative glycemic control and surgical site infection (abstract). Anesth Analg 2005; 100:S172

29. Golden SH, Peart-Vigilance C, Kao WH, Brancati FL: Perioperative glycemic control and the risk of infectious complications in a cohort of adults with diabetes. Diabetes Care 1999; 22:1408-14

30. Vriesendorp TM, Morelis QJ, Devries JH, Legemate DA, Hoekstra JB: Early post-operative glucose levels are an independent risk factor for infection after peripheral vascular surgery: A retrospective study. Eur J Vasc Endovasc Surg 2004; 28:520-5

31. Guvener M, Pasaoglu I, Demircin M, Oc M: Perioperative hyperglycemia is a strong correlate of postoperative infection in type II diabetic patients after coronary artery bypass grafting. Endocr J 2002; 49:531-7

32. McAlister FA, Man J, Bistritz L, Amad H, Tandon P: Diabetes and coronary artery bypass surgery: An examination of perioperative glycemic control and outcomes. Diabetes Care 2003; 26:1518-24

33. Turina M, Fry DE, Polk HC Jr: Acute hyperglycemia and the innate immune system: Clinical, cellular, and molecular aspects. Crit Care Med 2005; 33:1624-33

34. Geerlings SE, Hoepelman AI: Immune dysfunction in patients with diabetes mellitus (DM). FEMS Immunol Med Microbiol 1999; 26:259-65

35. Kersten JR, Warltier DC, Pagel PS: Aggressive control of intraoperative blood glucose concentration: A shifting paradigm? Anesthesiology 2005; 103 : 677-8

36. Raghavan M, Marik PE: Anemia, allogenic blood transfusion, and immunomodulation in the critically ill. Chest 2005; 127:295-307

37. Blumberg N, Heal JM: Immunomodulation by blood transfusion: An evolving scientific and clinical challenge. Am J Med 1996; 101:299-308

38. Leal-Noval SR, Rincon-Ferrari MD, Garcia-Curiel A, Herruzo-Aviles A, Camacho-Larana P, Garnacho-Montero J, Amaya-Villar R: Transfusion of blood components and postoperative infection in patients undergoing cardiac surgery. Chest 2001; 119:1461-8

39. Levi N, Sandberg T: Blood transfusion and postoperative wound infection in intracapsular femoral neck fractures. Bull Hosp Joint Dis 1998; 57:69-73

40. Agarwal N, Murphy JG, Cayten CG, Stahl WM: Blood transfusion increases the risk of infection after trauma. Arch Surg 1993; 128:171-6

41. Houbiers JG, van de Velde CJ, van de Watering LM, Hermans J, Schreuder S, Bijnen AB, Pahlplatz P, Schattenkerk ME, Wobbes T, de Vries JE, Klementschitsch $\mathrm{P}$, van de Maas AH, Brand A: Transfusion of red cells is associated with increased incidence of bacterial infection after colorectal surgery: A prospective study. Transfusion 1997; 37:126-34

42. Ali ZA, Lim E, Motalleb-Zadeh R, Ali AA, Callaghan CJ, Gerrard C, Vuylsteke A, Foweraker J, Tsui S: Allogenic blood transfusion does not predispose to infection after cardiac surgery. Ann Thorac Surg 2004; 78:1542-6

43. Fergusson D, Khanna MP, Tinmouth A, Hebert PC: Transfusion of leukoreduced red blood cells may decrease postoperative infections: Two meta-analyses of randomized controlled trials. Can J Anaesth 2004; 51:417-24

44. Hebert PC, Fergusson D, Blajchman MA, Wells GA, Kmetic A, Coyle D, 
Heddle N, Germain M, Goldman M, Toye B, Schweitzer I, van Walraven C, Devine D, Sher GD, Leukoreduction Study Investigators: Clinical outcomes following institution of the Canadian universal leukoreduction program for red blood cell transfusions. JAMA 2003; 289:1941-9

45. Sharma AD, Slaughter TF, Clements FM, Sreeram G, Newman MF, PhillipsBute B, Bredehoeft SJ, Smith PK, Stafford-Smith M: Association of leukocytedepleted blood transfusions with infectious complications after cardiac surgery. Surg Infect 2002; 3:127-33

46. Bratzler DW, Houck PM, Surgical Infection Prevention Guidelines Writers Workgroup, American Academy of Orthopaedic Surgeons, American Association of Critical Care Nurses, American Association of Nurse Anesthetists, American College of Surgeons, American College of Osteopathic Surgeons, American Geriatrics Society, American Society of Anesthesiologists, American Society of Colon and Rectal Surgeons, American Society of Health-System Pharmacists, American Society of PeriAnesthesia Nurses, Ascension Health, Association of Perioperative Registered Nurses, Association for Professionals in Infection Control and Epidemiology, Infectious Diseases Society of America, Medical Letter, Premier, Society for Healthcare Epidemiology of America, Society of Thoracic Surgeons, Surgical Infection Society: Antimicrobial prophylaxis for surgery: An advisory statement from the National Surgical Infection Prevention Project. Clin Infect Dis 2004; 38:1706-15

47. Bratzler DW, Houck PM, Richards C, Steele L, Dellinger EP, Fry DE, Wright C, Ma A, Carr K, Red L: Use of antimicrobial prophylaxis for major surgery: Baseline results from the National Surgical Infection Prevention Project. Arch Surg 2005; 140:174-82

48. Silver A, Eichorn A, Kral J, Pickett G, Barie P, Pryor V, Dearie MB: Timeliness and use of antibiotic prophylaxis in selected inpatient surgical procedures. The Antibiotic Prophylaxis Study Group. Am J Surg 1996; 171:548-52

49. Polk HC Jr, Lopez-Mayor JF: Postoperative wound infection: A prospective study of determinant factors and prevention. Surgery 1969; 66:97-103
50. Mangram AJ, Horan TC, Pearson ML, Silver LC, Jarvis WR: Guideline for prevention of surgical site infection, 1999. Hospital Infection Control Practices Advisory Committee. Infect Control Hosp Epidemiol 1999; 20:250-78

51. Executive summary of disease management of drug hypersensitivity: A practice parameter. Joint Task Force on Practice Parameters, the American Academy of Allergy, Asthma and Immunology, the American Academy of Allergy, Asthma and Immunology, and the Joint Council of Allergy, Asthma and Immunology. Ann Allergy Asthma Immunol 1999; 83:665-700

52. Salkind AR, Cuddy PG, Foxworth JW: Is this patient allergic to penicillin? An evidence-based analysis of the likelihood of penicillin allergy. JAMA 2001; 285:2498-2505

53. Moneret-Vautrin DA, Morisset M, Flabbee J, Beaudouin E, Kanny G: Epidemiology of life-threatening and lethal anaphylaxis: A review. Allergy 2005; 60:443-51

54. Petz LD: Immunologic cross-reactivity between penicillins and cephalosporins: A review. J Infect Dis 1978; 137 (suppl): S74-9

55. Daulat S, Solensky R, Earl HS, Casey W, Gruchalla RS: Safety of cephalosporin administration to patients with histories of penicillin allergy. J Allergy Clin Immunol 2004; 113:1220-2

56. Romano A, Gueant-Rodriguez RM, Viola M, Pettinato R, Gueant JL: Crossreactivity and tolerability of cephalosporins in patients with immediate hypersensitivity to penicillins. Ann Intern Med 2004; 141:16-22

57. Phillips E, Louie M, Knowles SR, Simor AE, Oh PI: Cost-effectiveness analysis of six strategies for cardiovascular surgery prophylaxis in patients labeled penicillin allergic. Am J Health Syst Pharm 2000; 57:339-45

58. Robinson JL, Hameed T Carr S: Practical aspects of choosing an antibiotic for patients with a reported allergy to an antibiotic. Clin Infect Dis 2002; 35:26-31

59. Hepner DL, Castells MC: Anaphylaxis during the perioperative period. Anesth Analg 2003; 97:1381-95 